\title{
Maternidades em contextos educativos do PIM/RS
}

\author{
Carin Klein' (iD) 0000-0002-1455-4413 \\ 'Universidade Luterana do Brasil, Programa de Pós-Graduação em Educação, Curso de \\ Pedagogia, Canoas, RS, Brasil. 92425-020 - ppgedu@ulbra.br
}

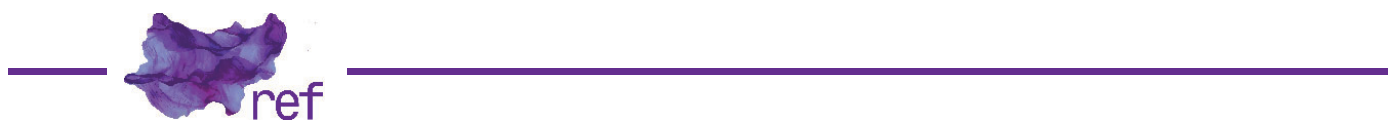

Resumo: O artigo é parte de uma pesquisa inspirada nos Estudos de Gênero, na qual problematizo um suposto caráter inerente às maternidades que, na "natureza" de todas as mulheres, coloca sentimentos, habilidades e comportamentos relacionados ao cuidado, à educação e à saúde das crianças, o que traz impactos às relações de gênero. O material empírico foi produzido por meio do cruzamento de informações de documentos oficiais e atividades que integram o Primeira Infância Melhor (PIM/RS). O artigo tensiona a produção das maternidades, no âmbito de uma política pública, compreendendo-a como uma instância educativa que propõe formas de investir na maternidade e de exercê-la. A forma de operacionalização da política permitiu apreender limitações muito concretas dos ensinamentos propostos pelo PIM, indicando a necessidade de refletir sobre as maternidades.

Palavras-chave: gênero; maternidade; políticas públicas; Primeira Infância Melhor.

\section{Motherhood in Educational Contexts of PIM/RS}

Abstract: The article is part of a research inspired by Gender Studies, which problematizes a supposed character inherent in motherhood that, in the "nature" of all women, puts feelings, skills and behaviors related care, education and health of children, which brings impacts on gender relations. The empirical material was produced by crossing information from official documents and activities that integrate Better Early Childhood (PIM / RS). The article tensions the production of motherhood, within the scope of a public policy, understanding it as an educational instance that proposes ways to invest in motherhood and to exercise it. The way of operationalization of the policy allowed us to apprehend very concrete limitations of the teachings proposed by the PIM, indicating the need to reflect on motherhood.

Keywords: gender; motherhood; public policies; Better Early Childhood.

\section{Maternidades en los contextos educativos de la PIM/RS}

Resumen: El artículo forma parte de una investigación inspirada en los Estudios de Género, que problematiza un supuesto carácter inherente a las maternidades que, en la "naturaleza" de toda mujer, pone en juego sentimientos, habilidades y comportamientos relacionados con el cuidado, la educación y la salud de los niños, lo que repercute en las relaciones de género. El material empírico se produjo mediante el cruce de información de los documentos oficiales y las actividades que componen Mejor Infancia Temprana (PIM/RS). El artículo tensa la producción de las maternidades, en el ámbito de una política pública, entendiéndola como una instancia educativa que propone formas de invertir en la maternidad y de ejercerla. La forma en que se aplica la política ha permitido aprehender limitaciones muy concretas de las enseñanzas propuestas por el PIM, indicando la necesidad de reflexionar sobre las maternidades.

Palabras clave: género; maternidad; políticas públicas; Mejor Infancia Temprana.

Neste artigo me proponho a discutir e a problematizar alguns ensinamentos desenvolvidos, no âmbito do Primeira Infância Melhor (PIM/RS), política pública voltada a ensinar às mulheres pobres determinadas formas de viver a gestação e exercer a maternidade, pois é por meio desses ensinamentos que o PIM posiciona e responsabiliza, sobretudo, as mulheres pelo desenvolvimento integral da primeira infância. Essa investigação está relacionada a um contexto de pesquisa mais amplo, caracterizado por estudos que buscam evidenciar de que forma algumas políticas de 
inclusão social, voltadas para a distribuição de renda, a elevação dos índices de escolaridade e o desenvolvimento infantil saudável atuam enquanto instâncias educativas, ao investirem em formas mais "adequadas" de exercer a maternidade e enunciarem-nas (Carin KLEIN, 2005; 2010).

Para realização desse trabalho, acompanhei as reuniões no PIM, na cidade de Canoas (RS), com o objetivo de apreender como o gênero, por meio do exercício da maternidade, funciona como um organizador das relações sociais e de poder (Emily MARTIN, 2006; Andrea O'REILLY, 2016; Valeska ZANELLO, 2018).

O PIM foi instituído em 2003, tomando como referência teórico-metodológica o programa cubano Educa tu Hijo. A seleção das famílias atendidas pelo PIM conta com critérios como: possuir cadastro no Programa Bolsa Família (PBF); aderir voluntariamente à política; ser gestante e/ ou possuir crianças, de até 6 anos, desassistidas da educação infantil; morar em localidades de maior taxa de mortalidade infantil e vulnerabilidade social. O site que apresenta as informações acerca da operacionalização da política indica o seu principal objetivo:

Política pública pioneira no Brasil, o Primeira Infância Melhor (PIM) é uma ação transversal de promoção do desenvolvimento integral na primeira infância. Desenvolve-se através de visitas domiciliares e comunitárias realizadas semanalmente a famílias em situação de risco e vulnerabilidade social, visando o fortalecimento de suas competências para educar e cuidar de suas crianças. [...] O PIM está voltado para o desenvolvimento pleno das capacidades físicas, intelectuais, sociais e emocionais do ser humano, e tem como eixos de sustentação a Comunidade, a Família e a Intersetorialidade (RIO GRANDE DO SUL, 2020, p. 1).'

Pode-se dizer que o PIM atua na constituição de estratégias educativas, tais como manuais, guias, vídeos e campanhas, servindo como base para a formação das "competências familiares" (RIO GRANDE DO SUL, 2016a, p. 9). São desenvolvidas por meio das modalidades de atenção e devem ocorrer sistematicamente nos domicílios, nas reuniões grupais e comunitárias. O principal elo entre o município e as famílias ocorre por meio dos(as) visitadores(as) domiciliares, responsáveis pelo cadastramento, planejamento, acompanhamento e execução das atividades educativas que devem ser desenvolvidas com as crianças em casa, pelas famílias.

Nesse contexto, o PIM completa 17 anos no estado do Rio Grande do Sul e serve como referência teórico-metodológica para o atual Programa Criança Feliz (PCF), do Governo Federal. O PCF$^{2}$ foi criado pelo Ministério do Desenvolvimento Social e Agrário, por meio do Decreto 8.869/2016, do dia 5 de outubro de 2016, vinculando-se ao Ministério da Cidadania e à Secretaria Especial de Desenvolvimento Social. ${ }^{3}$

O PCF visa fortalecer a "trajetória brasileira de enfrentamento da pobreza com redução de vulnerabilidades e desigualdades e potencializa a integração do acesso à renda com inclusão em serviços e programas" (BRASIL, 2017, p. 10) voltados para as gestantes, crianças na primeira infância e suas famílias.

Vale a pena lembrar que, durante os governos Fernando Henrique Cardoso (1995-2002), Luiz Inácio Lula da Silva (2003-2010) e, até o final do governo Dilma Rousseff (201 1-2016), assistimos a um crescimento constante na implantação e implementação de políticas públicas na esfera social, fundamentalmente sob a justificativa do crescimento econômico, do combate à pobreza, da redução da vulnerabilidade social e da inclusão social. Atualmente, esse cenário constituise no aprofundamento de cortes dos orçamentos públicos e na retração das políticas sociais, ${ }^{4}$ principalmente daquelas voltadas à educação, à saúde e à assistência social.

Ancorada nos Estudos de Gênero, em aproximação com autores(as) pós-estruturalistas, problematizo um suposto caráter inerente às maternidades que, na "natureza" de todas as mulheres, coloca sentimentos, habilidades e comportamentos relacionados ao cuidado, à educação e à saúde das crianças, o que traz impactos às relações de gênero (Elisabeth BADINTER, 1985; Mary DEL PRIORE, 1993; Adrienne RICH, 1995). Trata-se de desconstruir alguns desses sentidos, especialmente aqueles atrelados ao desenvolvimento das chamadas "competências familiares", como condição do desenvolvimento de uma primeira infância melhor, que tem sido alvo de investimentos constantes mediante ações, passeatas e campanhas governamentais, desdobrando-se de políticas públicas de inclusão social.

\footnotetext{
1 Para ver mais: http://www.pim.saude.rs.gov.br/site/o-pim/o-que-e/.

2 O Programa Criança Feliz foi instituído pelo Governo Federal, por meio do Decreto no 8.869 , de 5 de outubro de 2016, tendo como fundamento a Lei $n^{\circ} 13.257$, de 8 de março de 2016, que trata do Marco Legal da Primeira Infância. De acordo com o PCF, a primeira infância abrange os seis primeiros anos completos, ou seja, os 72 meses de vida da criança.

3 Vale dizer que o ex-ministro do Ministério da Cidadania, na gestão Jair Bolsonaro, Osmar Terra (2019-2020), também foi ministro do Desenvolvimento Social, no governo Michel Temer (2015-2018), Secretário de Saúde do Rio Grande do Sul nos governos Germano Rigotto (2003-2007) e leda Crusius (2007-201 1), período em que o PIM foi implantado como Programa e implementado como política pública, nesse Estado, em 3 de julho de 2006, com a Lei estadual $n^{\circ} 12.544$, de 2006 .

${ }^{4}$ A Portaria $n^{\circ} 2.436$, de 21 de setembro de 2017, propõe o congelamento por 20 anos dos recursos às políticas sociais.
} 
Com base nesses pressupostos, revisito a produção de alguns dados de campo, assim como discussões teóricas de minha investigação de doutorado (KLEIN, 2010), ${ }^{5}$ com o objetivo de evidenciar um conjunto de ensinamentos que procuram posicionar as maternidades no âmbito do PIM. O material empírico foi produzido por meio do cruzamento de informações de diferentes fontes: documentos oficiais e atividades que integram a política, conforme registradas em diário de campo.

Para isso, analiso de que forma esses ensinamentos envolvem e congregam fragmentos discursivos provenientes da puericultura, das políticas maternalistas e das psicologias do desenvolvimento, a fim de posicionar as maternidades no centro desses debates, para depois discutir algumas relações entre maternidades, no contexto educativo de saúde e cuidado vivenciado no campo de pesquisa. Parto das seguintes questões: que discursos (re)atualizam a produção das maternidades em políticas de inclusão social, tais como o PIM? De que forma mulheres "de carne e osso" (Claudia FONSECA, 1999) estabelecem relações entre maternidade e cuidado que escapam dos ensinamentos propostos pelo PIM? ${ }^{\circ} \mathrm{O}$ que essas relações podem nos ensinar?

Principalmente, por conta das desigualdades de gênero, as discussões acerca das maternidades e as tarefas reprodutivas são centrais na pauta dos debates feministas, fundamentalmente quando envolvem demandas relacionadas às políticas de inclusão social.

\section{Maternidades e feminismos}

Os debates feministas contemporâneos têm possibilitado outros modos de produção e de organização do espaço social, o que inclui, de diferentes formas, a produção científica, a formulação das políicas públicas e a reconfiguração de distintas relações sociais. Segundo Margareth Rago e Alfredo Veiga-Neto (2006), a crítica feminista tem evidenciado um pensamento que singulariza, conflita e subverte relações de poder e formas de sujeição de e entre homens e mulheres, acolhendo e estimulando, assim, a emergência de novas formas de feminilidades e de masculinidades. Com um caráter eminentemente político, crítico e desestabilizador, os feminismos têm potencializado movimentos que pretendem dar visibilidade às formas de produção dos conhecimentos na sua relação com a produção das subjetividades, mas também ao produzir uma avaliação contínua das próprias subjetividades e expressões éticas e estéticas que configuram e promovem.

Nesse sentido, as discussões sobre as maternidades, no âmbito dos Estudos Feministas, reúnem tendências teóricas plurais, marcadas pelo debate e pela divergência. Talvez um consenso possa ser indicado entre as diferentes correntes feministas: o de considerar as dimensões da esfera pessoal como importantes para o debate político, vendo esse espaço como um meio eficaz de análise das relações de desigualdade e essencialização, que também se (re)produzem no espaço público (Lucila SCAVONE, 2004).

Da metade do século XVIII até os dias atuais, interesses políticos e sociais em torno da configuração das maternidades têm difundido muitas orientações e imperativos de ordem pública e privada no que concerne à vida familiar, ao cuidado e à educação dos(as) filhos(as), ao trabalho, à educação, à saúde, ao consumo e à construção de políticas públicas, como o PIM e, mais recentemente, com a criação do PCF. Lucila Scavone (2004) diz que as discussões sobre as maternidades também colocam em debate a problemática da sua recusa e da sua negação, seja pelo aborto ou por meio da contracepção. Joana Maria Pedro (2003), ao discutir as práticas de infanticídio e de aborto no século XX, em Florianópolis, indica que esses temas são emblemáticos para visibilizar como os discursos enaltecedores das maternidades têm suas contradições, o seu avesso - enfim, eles evocam o caráter polissêmico das maternidades e do gênero. Pode-se dizer que, contemporaneamente, a discussão das maternidades tem trazido ainda um novo campo de possibilidades, tanto para o debate público quanto para o privado, ao ressaltar e visibilizar a responsabilização dos homens diante da contracepção, da reorganização do trabalho doméstico e, no que se refere ao cuidado e à educação dos(as) filhos(as), das paternidades.

Em grandes linhas, os feminismos têm sido delimitados historicamente, podendo-se pensar em três grandes movimentos. O primeiro refere-se às lutas universalistas, com ênfase na conquista por igualdade mediante a luta por direitos políticos e civis; um segundo movimento diz respeito às lutas pela afirmação das diferenças, localizando as mulheres como sujeitos de direitos específicos; e um terceiro movimento aproxima-se das análises de autores(as) pós-estruturalistas,

\footnotetext{
${ }^{5}$ O trabalho de campo, de caráter etnográfico, foi realizado no município de Canoas (RS) e ocorreu ao longo de onze meses, de março de 2007 até fevereiro de 2008, por meio da observação e do registro das atividades referentes ao PIM e, ainda, da seleção e da análise dos documentos oficiais.

6 Em outro artigo, analiso como o tema da infância é abordado no âmbito da política Primeira Infância Melhor (PIM/ RS), a fim de responsabilizar as mulheres-mães pelo desenvolvimento infantil saudável. Nesse sentido, indago: Que discursos (re)atualizam a produção da infância em políticas de inclusão social, tal como o PIM? Que enunciados sobre o desenvolvimento infantil são acionados para a responsabilização das mulheres-mães? (KLEIN, 2018).
} 
encaminhando-nos a pensar que os termos "homem", "mulher", "maternidade" e "paternidade" não têm em si sentidos fixos e universais, mas se constituem de forma relacional e são o resultado nunca acabado de processos sociais, históricos, culturais e linguísticos (SCAVONE, 2004).

Minha aproximação das análises sobre maternidades, em contextos de saúde, educação e cuidado, provém da filiação a esta última vertente, com o propósito de analisar o caráter constitutivo da linguagem e do gênero, além de historicizar algumas categorias, como mulher, mãe, homem e pai, muitas vezes, tomadas no presente como dadas a priori ou "realidades evidentes" (Joan SCOT, 2002, p. 2). ${ }^{7}$ No âmbito dessa discussão, torna-se importante pensar as maternidades a partir do conceito de gênero, tomando-o "[...] como referência a qualquer construção social que tenha a ver com a distinção masculino/feminino, incluindo as construções que separam corpos 'femininos' de corpos 'masculinos'" (Linda NICHOLSON, 2000, p. 9). Isso inclui tanto as dimensões relativas a comportamentos, habilidades e sentimentos, quanto "as próprias formas como o corpo aparece" (NICHOLSON, 2000, p. 9) e segue sendo representado no âmbito das políticas públicas. Com isso, não se busca negar a materialidade dos corpos ou a existência de elementos que diferenciam mulheres de homens, mas refletir sobre os sentidos que ele(s) adquire(m) em uma determinada cultura, além de rejeitar a existência de qualquer sentido inato, preexistente ou universal que, muitas vezes, é utilizado para explicar e/ou justificar determinadas diferenças e hierarquias sociais. $O$ uso do conceito de gênero acentua ainda a compreensão da maternidade no plural, na medida em que admitimos as conflitualidades e ambivalências como forças inerentes aos processos culturais que as constituem e distinguem, além de serem atravessadas por marcadores como pertencimento socioeconômico, escolaridade, raça/etnia, geração, nacionalidade, religião etc. Ou seja, as justificativas que acompanham a educação da maternidade, a partir de noções essencialistas, universais e a-históricas, evidenciam um caráter reducionista, linear, que necessita ser contestado (Dagmar MEYER, 2017).

Colocar sob tensão alguns modos de organização do social, tais como aqueles que buscam produzir e naturalizar formas mais "adequadas" de participar da maternidade e de exercêla, descritas em inúmeras matérias de jornais e revistas, cartilhas, guias e manuais, considerandose que vários deles têm servido como referência para nortear ações e políticas sociais na área da educação e(m) saúde, torna-se um exercício produtivo e político relevante. Nessa esfera, outra dimensão importante a considerar refere-se à ausência e à obliteração do gênero em muitas discussões por parte do Estado, sobretudo nas políticas voltadas para a população maternoinfantil e demais processos comunicacionais (Renata TOMAZ, 2015). Nesse sentido, os processos de significação que envolvem os corpos e as maternidades atuam na produção de diferenças e hierarquias envolvidas nas identidades sociais que assumimos, pelas quais passamos a nos reconhecer como mulheres, homens, mães e pais de determinados tipos. Gênero é um dos marcadores sociais que, articulado com pobreza, sexualidade, raça, geração e escolaridade, pode atuar na constituição e na significação dos "corpos de risco" ou "vulneráveis", por exemplo, sobre os quais o PIM investe.

Com base nessa discussão, argumento que propostas governamentais como o PIM e o PCF partem do entendimento de que a condução das famílias é central para o debate que permeia a educação e(m) saúde ali proposta. No que se refere a essa condução, pode-se perceber, tanto a partir da leitura dos documentos que norteiam as ações, quanto por meio da participação nas atividades, já mencionadas, a articulação entre os discursos provenientes de diferentes campos do conhecimento, os quais reproduzem e (re)atualizam lições e formas de cuidar específicas do investimento em ações programáticas para promoção do desenvolvimento infantil.

Argumento que ensinamentos e orientações dirigidos à formação das "competências familiares", no que se refere a este estudo, envolvem conhecimentos da puericultura e das políticas maternalistas preconizadas desde o início do século XX, bem como os discursos da psicologia do desenvolvimento, que investem na representação da mãe cuidadora e da criança "natural". Parto do pressuposto de que, no contexto contemporâneo, essa (re)atualização de discursos veiculados no campo das políticas de educação e $(\mathrm{m})$ saúde funciona no sentido de produzir e sustentar uma relação entre a educação das famílias e a resolução de problemas sociais mais amplos.

\section{(Re)atualizando discursos que sustentam e constituem o PIM}

O aparecimento das chamadas "competências familiares" para o desenvolvimento da "primeira infância melhor" torna-se um dos elementos centrais na discursividade que sustenta e constitui o PIM e, atualmente, O PCF, uma vez que investe em uma rede articulada de ações educativas voltadas para a promoção do desenvolvimento infantil nomeado como "integral e

\footnotetext{
7 Essa aproximação traz tensões para os debates contemporâneos, pois se, por um lado, contribui e atua na direção "[...] de desconstruir o discurso normativo sobre dominação e poder na sociedade", por outro lado, as análises podem esvaziar a "[...] possibilidade de saídas coletivas, chocando-se com a proposta do movimento feminista" (SCAVONE, 2004, p. 12), que durante muito tempo buscou afirmar uma relação específica das mulheres nas sociedades.
} 
saudável". Ao lermos as orientações e sugestões de atividades expressas nos "Guias", ${ }^{8}$ entendemos que se tornar um sujeito "competente", nesse contexto, demanda adquirir "conhecimentos específicos" sobre o desenvolvimento integral das crianças, ficando em evidência não apenas a discussão e a reconfiguração do que é ser criança, mas também a produção de significados específicos em torno de funções familiares e da produção de cuidados direcionados para o sujeito criança.

Maria Martha de Luna Freire (2008) discute como as funções femininas, centradas nas funções maternas, assumiram destaque no âmbito do projeto modernizador nacionalista, sobretudo no Brasil dos anos 1920. O apogeu dos discursos maternalistas ocorreu nessa década, propondo e difundindo, com bases científicas, uma redefinição para a maternidade. As bases para o exercício dessas maternidades estariam concentradas na esfera doméstica, mas também deveriam incorporar uma dimensão patriótica e pública, a partir e em função da qual os(as) filhos(as) seriam concebidos(as) como "futuros(as) cidadãos/cidadãs", simbolizando a esperança e a viabilidade da nação. Justificado em bases científicas, "o investimento na primeira infância como aposta de futuro" (RIO GRANDE DO SUL, 2007) passa a ser um enunciado reproduzido e atualizado no âmbito do PIM. Em uma publicação elaborada pelo município de Canela9 e destinada a gestores(as) municipais e à sociedade, intitulada Como realizar a semana do bebê em seu município: 10 anos priorizando a primeira infância em Canela, podemos ver:

Hoje, graças às recentes descobertas da ciência, é melhor compreendida a importância vital dos primeiros anos de vida, para todo o desenvolvimento futuro do ser humano. É no início de sua existência que todos os sistemas vitais organizam os alicerces de seu funcionamento posterior. Não é diferente com a nossa espécie. Esse conhecimento científico nos leva à necessidade de investir cada vez mais em políticas públicas para o desenvolvimento integral da primeira infância, se quisermos um mundo melhor para se viver. No Rio Grande do Sul, executamos a mais abrangente política de cuidados nessa área, existente no Brasil. Desde 2003, trabalhamos com um programa denominado Primeira Infância Melhor (PIM) (CANELA, 2010, p. 9).

Baseada em estudiosos como John Bowlby e René Spitz, autores da teoria da vinculação e da privação materna, a publicação faz referência à importância "crucial da gestação e dos primeiros anos de vida para o desenvolvimento total do ser humano" (CANELA, 2010, p. 13) e destaca os "efeitos" escolares salutares da relação mãe-filho, estimulada com a realização da "Semana e adotada como programa de orientação às mães nas unidades de saúde" (CANELA, 2010, p. 18). Um depoimento que envolve conhecimentos técnicos e políticos indica as diferentes posições de sujeito ocupadas por uma mulher (vice-prefeita, ex-professora e ex-coordenadora da Semana do Bebê no município, em 2009), dando-lhe legitimidade e poder para traçar um caminho natural entre maternidade, saúde e cuidado:

\begin{abstract}
Autoridades municipais e estaduais, profissionais da área da saúde, professores e acadêmicos não têm dúvidas: a Semana do Bebê mudou o comportamento da comunidade de Canela com respeito às suas gestantes e crianças e é, hoje, exemplo de intervenção para brasileiros e estrangeiros. Coordenadora da Semana de 2009, a vice-prefeita e ex-professora Lesli Serres de Oliveira diz que já é possível notar nas escolas os efeitos da relação mãe-filho, pregada pela Semana e adotada como programa de orientação às mães nas unidades de saúde. Lesli afirma que as crianças estão mais ativas e participantes: "isso é notório nas nossas escolas. Antes tínhamos crianças acabrunhadas, quietas ou briguentas. Hoje elas estão mais participantes. Têm carinho da família, que também se aproxima mais da escola" (CANELA, 2010, p. 18).
\end{abstract}

Assim, publicações, documentos, campanhas, cartazes e instituições públicas e privadas investem nas mulheres e educam-nas a incorporar uma determinada forma de ser mãe. Multiplicam-se, pois, os locais, as instituições e os sujeitos envolvidos na produção de significados que vinculam o exercício da maternidade ao desenvolvimento infantil saudável, ao sucesso escolar e ao investimento na infância como projeto de futuro.

Voltando ao Brasil dos anos 1920, Freire (2008) sinaliza que os médicos passam a ganhar grande destaque para traçar as novas bases científicas das maternidades modernas, contribuindo, de maneira eficaz, para a constituição de um "ideário da maternidade científica" (FREIRE, 2008, p. 161). Por meio de uma detalhada pedagogia, tratava-se de ensinar as mulheres, de forma didática e acessível, a incrementarem suas ações domésticas, de modo que pudessem aprender a ser e desdobrar-se entre a "mãe educadora" e a "mãe enfermeira" (Ana Paula MARTINS, 2008,

\footnotetext{
${ }^{8}$ O Guia da família e o Guia da Gestante (RIO GRANDE DO SUL, 2016a; 2016b) estão em sua 7a edição e são usados como suporte pelos(as) técnicos(as) e visitadoras, bem como por famílias e gestantes das comunidades em que o PIM se insere. Outros guias importantes formulados para os(as) gestores(as) são o Guia de Orientação para GTM, Monitor e Visitador. Contribuições para políticas na área do desenvolvimento infantil (RIO GRANDE DO SUL, 2007) e Como investir na primeira infância: um guia para a discussão de políticas e a preparação de projetos de desenvolvimento da primeira infância.

${ }^{9}$ A elaboração do material contou com o apoio da Ullbra e da Unicef e tem como objetivo difundir aos(às) gestores(as) públicos(as) formas de produzir, em seus municípios, a chamada Semana do Bebê, que também ocorre em Canoas (RS).
} 
p. 150), conforme recomendado tanto nos artigos de revistas femininas, quanto nos manuais de puericultura.

Foi ainda a partir do projeto higienista e da institucionalização dos conhecimentos médicos preconizados nas faculdades de medicina que se afirmaram os discursos maternalistas brasileiros, formulados no final do século XIX. Enunciados por médicos higienistas, juristas, educadores(as), líderes religiosos(as), empresários(as), feministas e profissionais de diferentes áreas, trataram não apenas da redefinição e da pedagogização das maternidades, mas também da discussão da infância e das funções familiares, que adquirem força ao se afinarem com os interesses das elites intelectuais republicanas e incidirem sobre a produção de leis e de medidas de proteção social às mães e filhos(as). Nesse cenário, as maternidades passam a configurar-se como um elemento central de teorias e práticas reivindicatórias feministas e como um "veículo ideal para difusão de uma nova cultura", capaz de influenciar o progresso e a viabilidade da nação (FREIRE, 2008, p. 155).

As maternidades, entendidas como um "valor social" e um "dever patriótico", necessitam de intervenção a fim de alinharem-se com as questões econômicas, demográficas, sanitárias e patrióticas (FREIRE, 2008, p. 155). Porém, esse ideário também acionava uma importante tensão em torno das maternidades, o que ainda pode ser visualizado na atualidade: tratava de manter a marca da essencialidade, preconizada mediante uma suposta existência universal do instinto maternal, ao mesmo tempo em que o reconhecia como insuficiente, precisando incorporar "novos" conhecimentos exigidos pela modernidade, como a puericultura, a fim de aperfeiçoá-la.

Segundo Freire (2008; 2014), mesmo que a "maternidade científica" se traduzisse como uma imposição da classe médica sobre as mulheres, a produção dessas maternidades não representou simplesmente um reforço das desigualdades de gênero, pois, enquanto associava essa função a uma dimensão biológica, aproximando-a do âmbito doméstico, também servia para ampliar a participação e o poder das mulheres, incitando-as a ocupar a posição de mães na sociedade. Assim, as maternidades, ao adquirirem o status de função social, imbuídas de um caráter científico, passaram a borrar as fronteiras entre as esferas públicas e privadas, contribuindo para a defesa de interesses próprios e de ampliação do lugar das mulheres na família e na sociedade, além de estimularem o lançamento de estratégias para a obtenção de alianças, negociação, resistências, parcerias, benefícios e inserção na arena política, tornando-as sujeitos e objetos das políticas de proteção.

André Ricardo Pereira (1999) discute o discurso que sustentou a criação do primeiro programa estadual de proteção à maternidade, à infância e à adolescência no Brasil, com a implantação do Estado Novo, sob execução do Ministério da Educação e Saúde e do Departamento Nacional da Criança. A realização desse projeto educativo "cientificamente correto" (PEREIRA, 1999, p. 168), propagado pelo Estado, vinculava-se a uma noção de infância como algo que precisava ser acompanhado de "carinho e afeto"; para isso, essa infância tinha que contar com o auxílio e os conhecimentos de médicos(as), professores(as), autoridades públicas e, pela condição feminina, das mulheres em geral.

Com a ampliação da pobreza nos grandes centros urbanos e a ameaça à propriedade privada, começou-se a ver a criança distante de uma pureza e inocência inatas, aparecendo e nomeando-se, nesse contexto, o "menor" ou o infrator, em oposição à noção de "criança natural". Pereira (1999) argumenta que, com a vigência do individualismo, se investe no indivíduo como um meio de manter a estabilidade das famílias e de promover a integração social, ao invés de desvendar e investir nos nexos socioeconômicos.

Iniciativas como os "Postos de Puericultura", "Gotas de Leite" e "Missões da Infância Feliz" tornavam-se ações que buscavam suprir as deficiências das famílias, atuando na promoção de sentimentos e hábitos capazes de fortalecer a "referência básica da identidade social [...] quer dizer, a mobilização em favor do projeto de bem criar os 'filhos da Nação'" (PEREIRA, 1999, p. 179). Pautado por valores da classe média, o modelo de família esperado pelo Departamento Nacional da Criança era definido pelo marido que trabalhava, ocupando o lugar de "chefe", e pela mulher, desvinculada de qualquer atividade fora de casa, uma vez que isso implicava a associação com "problemas sociais"; portanto, seu lugar na família consistia em ficar em casa, para ter tempo de dedicar-se à educação dos(as) filhos(as).

No que se refere à "naturalização" das relações familiares, Cynthia Sarti (1999) indica que, por se tratar de um fenômeno universal e fundamentar-se em bases como o acasalamento, o nascimento, o crescimento e o envelhecimento, há a tendência de se pensar a família fora das relações sociais, o que a transforma em uma entidade positiva, alicerce de formação dos indivíduos e terreno fértil para discursos normativos. Para a autora (1999), pensar as famílias como um lugar de intervenção para a educação de crianças e jovens exige reconhecer os conflitos que Ihes são inerentes, as vulnerabilidades a que estão expostas, os significados que atribuem às suas experiências, o acesso (ou não) a determinados recursos (e sua eficiência), o que inclui levar em conta os contextos socioculturais em que estão inseridas. A ausência dessas reflexões pode significar tanto a dificuldade em desenvolver propostas de cunho educacional por parte 
das equipes que com elas trabalham, quanto o favorecimento da violência, da exclusão e da vulnerabilidade que se pretende diminuir, já que, na maior parte das vezes, não se acolhem e não se criam canais de escuta e de negociação dos significados que atravessam essas relações.

Desse modo, compreender e trabalhar a partir de modelos idealizados pode colocar em jogo duas dimensões importantes: por um lado, partir de uma referência idealizada de famílias "projetada[s] num dever ser" pode significar não levar em conta suas vivências, entendimentos e necessidades e, consequentemente, a possibilidade de resolução de seus conflitos; por outro, "a idealização de si, por parte dos profissionais", que, amparados por sua formação técnica, expressam uma tendência de hierarquização do saber, em que alguns conhecimentos preponderam sobre outros, podendo-se reproduzir e ampliar os "mecanismos que instituem a desigualdade social" (SARTI, 2008, p. 34-35). Em um dos encontros na comunidade, foi narrada uma situação que me fez refletir sobre as ações das políticas e esse movimento de idealização:

\begin{abstract}
Antes de iniciar um dos encontros na comunidade, falou-se na gestante Clarisse, ${ }^{10}$ que tem 10 filhos (e já perdeu cinco). A visitadora dessa família nos contou que já conseguia entrar na casa dessa mãe e que considerava muito difícil mexer naquela organização familiar. Contou-nos que, em muitas visitas, ela não conseguiu entrar, ficando no pátio durante o trabalho com as crianças. Diante desse comentário, um dos técnicos disse que aquela era uma "família préPIM", pois ainda não havia aderido à metodologia, que uma "família PIM" acolhe a visitadora, recebe a Estratégia de Saúde da Família (ESF), funciona e se organiza melhor. Comentou-se, ainda, sobre o marido dessa mulher - que não dava abertura, parecendo controlador, como se fosse um galo cuidando do território, mas que ele até já havia melhorado (DC).
\end{abstract}

Nesse contexto, ser uma "família pré-PIM", conforme mencionado pelo técnico e reiterado pela fala da visitadora, expressava ser anterior a algo, talvez à forma idealizada de família pensada pelas políticas. Isso confirmava que se tornar uma "família PIM" significava não só aderir aos objetivos da política, como também acolher a visitadora e os agentes comunitários de saúde, seguir metodologias, incorporar ensinamentos, abrir as portas da casa e, com isso, dar-lhes autorização para intervir em suas formas de organização e cuidado dos(as) filhos(as), mostrando, nitidamente, de que modo eram acionados alguns pressupostos pedagógicos na tentativa de colocar sob a norma (e tornar competentes) determinados indivíduos. O homem-pai era narrado como alguém que exercia um lugar de autoridade e dificultava as ações do PIM - não "dava entrada", impedia as intervenções que incidiriam nas formas de organização familiar -, mas que também não era chamado a participar das ações.

Por meio do acompanhamento das atividades do PIM, evidencia-se que é a mulher, pela maternidade, que se torna alvo da intervenção das políticas públicas referentes à criação das crianças e à organização familiar. É ela que precisa buscar o auxílio e a orientação, receber a visitadora e a agente comunitária de saúde, ter paciência, contar histórias, brincar, estimular, levar para passear, organizar a casa, cozinhar, além de, muitas vezes, buscar complementação de renda para a família. Colocando-se as crianças como foco de atenção e intervindo-se nas relações familiares, mediante estratégias centradas na interpelação e na educação das mulheres-mães, (re)atualizam-se diferenças e desigualdades de gênero que pouco contribuem para ampliar o que se denomina como família e cuidado.

Assim, incorporar ensinamentos e atuar como uma "família PIM", como discuti há pouco, tornam-se objetivos bastante próximos de argumentos preconizados nos discursos da puericultura, da psicologia do desenvolvimento e no âmbito dos projetos higienistas, uma vez que tratavam e tratam de (re)colocar a mulher e as maternidades no centro dos debates e das políticas públicas. Porém, pode-se dizer que há um deslocamento - atualmente, a mulher é convocada tanto a aprender a cuidar das crianças, o que a vincula ao âmbito doméstico, quanto a aprender uma atividade laboral, com o propósito de manter ou complementar a renda familiar. ${ }^{11}$ Se antes as mulheres eram tomadas como as "únicas" responsáveis pelos(as) filhos(as), hoje em dia, políticas de distribuição de renda, como o PBF, dirigem-se "preferencialmente" à mulher, para que ela possa (sacar o benefício e) assumir a função de "responsável legal pela família" (BRASIL, 2006).

Martins (2008) discute ações voltadas à puericultura ${ }^{12}$ como projeto educativo e formativo, que vigorou durante o século XIX. Essa especialidade médica passou a constituir-se por meio de ensinamentos e aconselhamentos dirigidos às mulheres, outorgando, fundamentalmente, às mulheres-mães a responsabilidade por educar e cuidar das crianças pequenas. Para a autora

\footnotetext{
10 Todos(as) os(as) participantes da pesquisa assinaram um termo de consentimento livre e esclarecido e os nomes aqui citados são fictícios.

11 Nos Centros de Referência de Assistência Social (CRAS), as mulheres de baixa renda são inscritas para atuar em frentes de trabalho emergencial, que geralmente consistem na limpeza de órgãos públicos, como contrapartida ao recebimento de uma cesta básica mensal. Em Canoas (RS), também ocorriam as ações Próximo Passo e Mulheres Construindo Autonomia, iniciativas do governo federal, por intermédio do Programa Bolsa Família (PBF), a fim de capacitar homens e mulheres a atuarem na construção civil como pedreiros(as) e azulejistas.

12 Nesse artigo, a autora analisa três livros de aconselhamento médico para as mães, publicados entre as décadas de 1930 e 1960. Os autores são: Carlos Prado, Martinho da Rocha e Rinaldo de Lamare.
} 
(2008), desde o século XVIII, mas principalmente no século XIX, a criança agregou maior valor e visibilidade, ampliando-se as discussões não apenas sobre os métodos educativos e as formas de cuidar das crianças, mas também sobre a aproximação entre mulheres e médicos, que passaram a figurar na cena do parto, nos cuidados com a gravidez, nos cuidados do bebê recém-nascido e nas doenças infantis. Foi pela força e notoriedade dos discursos médicos e da puericultura que se produziram formas de divulgação de assuntos como alimentação, vestuário, higiene e comportamento, a fim de ampliar, junto às mulheres-mães, e mais especificamente entre as mães pertencentes a determinados segmentos da população, a noção de que a criança bem orientada e conduzida constitui uma aposta ou promessa de futuro.

Primeiramente, foram as mulheres das classes mais abastadas e letradas que se tornaram alvo de tais ensinamentos, mas estes também precisavam chegar às mulheres-mães das classes populares, que continuavam alheias aos conhecimentos da nova ciência. Tornou-se necessário, então, ampliar as formas de comunicação entre os especialistas e as mulheres para traduzir-lhes as lições que deveriam cumprir em relação ao desenvolvimento infantil. Foi pelo uso de uma linguagem mais simples e didática que os médicos trataram de popularizar esses conhecimentos, passando a escrever livros, realizar palestras e cursos, responder cartas que eram enviadas às seções de jornais e revistas, além de utilizar o rádio, considerado um meio de comunicação de massa no século XX (MARTINS, 2008).

É a partir da década de 1960 que aquilo que venho chamando de uma pedagogização das maternidades começou a colocar em evidência as relações afetivas entre mães e filhos(as) (KLEIN, 2018). Se no modelo educativo anterior pensava-se na redução da mortalidade infantil, vinculando-a a doenças relacionadas à nutrição e à falta de higiene, na nova fase, introduziamse as dimensões relacionadas a aspectos de saúde mental, em que "mães ausentes" ou "superprotetoras" se tornavam alvo da discussão pública (veiculada na voz de médicos por meio das lições da puericultura, entrevistas de rádio, artigos de jornais e revistas femininas), uma vez que elas podiam colocar em risco o equilíbrio psíquico das crianças. Assim, reforçava-se e ampliava-se a experiência da maternidade conforme um modelo extremamente normalizador e de dedicação exclusiva, culpando as mulheres que desejavam trabalhar ou seguir uma carreira profissional e gerando-lhes insatisfação, além de isolá-las, mais uma vez, em formas naturalizadas e romantizadas da díade mãe-filho(a) (MARTINS, 2008).

Por meio da fala das visitadoras, foi possível evidenciar alguns fragmentos discursivos que tratavam de avaliar e mensurar a conduta das mulheres-mães a partir de pressupostos científicos. Ao estabelecer relações entre maternidade, saúde e cuidado, uma delas disse o seguinte:

\begin{abstract}
Eu acho que, se tu não tiveres aquele cuidado na gravidez, se tu não te cuidares, desde a higiene até a alimentação, indo ao médico, fazendo o pré-natal direitinho, os exames que são importantes, tudo isso vai influenciando em tu seres uma boa mãe. Não ser boa de boazinha, mas ser boa de poder suprir todas as necessidades, tanto quando o feto que está ali dentro de ti, por um período de nove meses, quanto depois. Se tu não mantiveres esse equilíbrio de começar a ter uma boa higiene contigo e com o teu bebê, saber que tem que dar banho, lavar as partes direitinho, cuidar para não ter infecção, assaduras. Aquilo que a mãe não faz, mais tarde, o filho não vai conseguir fazer também, porque ela não consegue passar aquilo para o filho, desde lá de dentro da barriga. Eu acho que saúde é como se tu tivesses um vínculo de amor, se tu não tiveres amor por ti, [não] te cuidares, tu também não vais conseguir fazer isso com o teu filho, e mais tarde também, quando teu filho crescer, ele também não vai conseguir ter isso (DC).
\end{abstract}

É no interior dos discursos voltados ao desenvolvimento infantil que a normalização das funções e competências familiares, sobretudo maternas, necessita ser constantemente reiterada e aprimorada. Cabe dizer que não há uma linearidade ou homogeneidade nesses processos e relações, na medida em que fazem parte dos sistemas simbólicos da linguagem e da representação, porém atuam fortemente sobre a produção de imperativos, recomendações e ensinamentos, como os propostos no âmbito das políticas de inclusão social.

Sob argumentos contemporâneos, os sentidos atribuídos às maternidades e à saúde expandem-se sob justificativas embasadas na ampliação de técnicas de visualização, em que o útero passa a ser significado como um "ambiente fetal saudável" que carrega "um ser desde já", e a mulher que não se vincula a essa premissa passa a ser vista como ignorante ou negligente.

O útero passa a ser qualificado como uma espécie de "ambiente sentimentalizado" - o argumento da visitadora vincula-o à saúde do feto, conquistada ainda nesse útero-ambiente, com a capacidade da gestante de amar e cuidar de si mesma, condição para que ela se torne capaz de aprender a amar e cuidar do(a) futuro(a) filho(a) (MEYER, 2006; Maria SCHWENGBER, 2006). Para ser uma "boa mãe", a mulher precisa empenhar-se, manter o equilíbrio, envolverse no cuidado e na educação do(a) filho(a) desde a gravidez, reiterando-se a importância e o desempenho da mulher enquanto gestante para o sucesso (ou não) do desenvolvimento infantil. Ressignificada, uma determinada forma de exercer as maternidades funciona como o elemento principal e constitutivo do que se entende por desenvolvimento infantil saudável. 
O argumento da naturalização das funções e competências familiares toma força com os discursos da psicologia do desenvolvimento e a divulgação da noção da criança "natural", que alicerça um determinado projeto educativo de infância. A representação de infância, cujo desenvolvimento é "natural", progressivo e contínuo, pressupõe um ambiente (em um corpo) sob forma de "útero" acolhedor, protetor e amoroso, principalmente a partir da incitação das mulheres a que ocupem a posição de mães dedicadas, atenciosas, presentes o tempo todo, capazes de ajustar-se "naturalmente" à tarefa de educar e de suprir todas as necessidades dos(as) filhos(as) e da família (KLEIN, 2018).

Para ampliar a reflexão sobre a educação para as maternidades que ocorrem no âmbito do PIM, argumento, a partir de minha inserção no campo de pesquisa, acerca de uma modalidade de atenção prevista na metodologia da política. Nesse sentido, trago fragmentos da história de Elena, que considero emblemática em meu percurso de investigação; não que ela represente o grupo de mulheres que frequentavam os encontros, mas para discutir alguns elementos daquele contexto e que me possibilitaram compreender e problematizar aspectos importantes sobre as formas de negociar, socializar-se, aprender e resistir daquelas mulheres e de suas famílias, no âmbito de políticas e inclusão social como o PIM.

\section{Negociando os sentidos das maternidades no âmbito do PIM/RS}

Nesta escrita, pretendo problematizar alguns sentidos atrelados às maternidades e às relações de gênero; porém, ao considerar que a centralidade da linguagem é recorrente nessa perspectiva, posso narrar sem escapar das formas de produção de saber, controle e regulação que me proponho a discutir e analisar. Ao perguntar ao grupo de técnicos(as) sobre quem exercia a função de "cuidador" - termo difundido nos "Guias" e nas capacitações realizadas pelo Estado -, ou seja, sobre quem ocupava o lugar de referência na família para receber e aprender os ensinamentos, eles(as) se mostraram unânimes nas respostas:

É a mãe, porque isso é uma realidade, não adianta a gente dizer "o cuidador". O cuidador que a gente tem e que está em casa é $90 \%$ a mãe. Se não é a mãe, é a tia ou é a irmã mais velha ou é a avó; em último lugar, o pai, um primo ou tio. Isso é uma realidade (DC).

A fala dos técnicos(as) indica o quanto eles(as) também se tornam sujeitos das políticas de inclusão social e de sua feminização, pois são posicionados(as), assim como as usuárias, no âmbito das linguagens divulgadas nos guias do PIM, nas capacitações nos municípios, nas imagens dos cartazes expostos nos Centros de Referência de Assistência Social (CRAS), nas propagandas que veiculam o PBF, entre outros locais. São materiais que trazem a presença constante de marcadores de gênero reiterados pela via da normalização e da responsabilização das maternidades "como parte da estratégia de Estado no cuidado das famílias" (Priscila DETONI; Paula MACHADO; Henrique NARDI, 2018, p. 4).

A maioria das mulheres que frequentava as reuniões do PIM morava há anos no Bairro Mathias Velho, em Canoas (RS), e tinha vindo do interior do estado, tendo participado do início das invasões, consideradas irregulares até hoje. Em sua grande maioria, as mulheres cadastradas no PIM possuíam pouca escolaridade, mas algumas haviam concluído o ensino médio e buscavam, juntamente com suas famílias, emprego e melhores condições de vida. Muitas delas não trabalhavam em empregos formais; às vezes, faziam alguma faxina fora de suas casas, trabalhavam em supermercados próximos ou como auxiliares de cozinha. Geralmente, partilhavam as responsabilidades familiares com seus companheiros, que, segundo elas, viviam de bicos, realizados, principalmente, na construção civil e na reciclagem de materiais.

Foi assim que conheci Elena, tomando-a não apenas como um exemplo representativo de interação social naquela comunidade, mas como alguém que era posicionada como foco central - de mãe e cuidadora - para propiciar o desenvolvimento infantil saudável e que, assim como outras mulheres, demonstrava, ao longo dos encontros, possuir limitações muito concretas para efetivar o que se esperava dela no PIM. Estava grávida de oito meses e, aos poucos, foi mobilizando não só meu olhar e afeto, mas também uma intensa reflexão sobre a sua forma de viver, de relacionar-se no grupo e de encontrar "saídas" para as dificuldades do cotidiano. Fomos (os(as) técnicos(as) e eu) percebendo que ela possuía "limites", noção que coloco sob rasura, para compreender alguns assuntos simples que eram abordados naquele espaço. Ela parecia não ouvir o que era tratado, ficava dispersa e/ou tentando estabelecer um contato mais direto com algum(a) outro(a) participante. Com o tempo, descobri que ela não sabia ler, assinava com letra de forma apenas seu primeiro nome e, geralmente, se expressava com um vocabulário bastante restrito, falando bem alto e/ou interrompendo alguém do grupo. Demonstrava ser desatenta e rude, segundo nossos padrões, ao mesmo tempo em que, muitas vezes, se mostrava paciente e amorosa com seus(suas) filhos(as); era assídua aos encontros semanais, mas quase sempre chegava atrasada, xingando e trazendo quatro ou cinco dos(as) seus(suas) sete filhos(as). No diário de campo, descrevia as informações que reunia: 
Vejo Elena chegar acompanhada de seus(suas) cinco filhos(as) pequenos(as) (dessa vez, todos(as) estão de chinelinho naquele dia frio) e com sua bebê recém-nascida no colo. Elena tem um menino com 12 anos que estuda numa escola especial; segundo a mãe, ele não aprendeu a ler nem a escrever. Observo que ele tem um afundamento no crânio, dificuldade para falar, Ihe faltam os movimentos de um dos braços e em uma das pernas. Neste dia, ele nos contou que havia pisado em um prego e mostra seu pé machucado. O técnico diz a ela que precisa sair dali e levá-lo à UBS, pois é muito perigoso ter tétano. A bebê de Elena é uma menina e, apesar da aparência descuidada e suja de toda a família, de acordo com o meu olhar, ela está muito arrumadinha. Acho uma linda menina, muito cabeluda. Enquanto todos olham a bebê, Elena diz ao técnico: "Tu não vai me arrumar uma visitadora?". Ele Ihe explica novamente que, no momento, nenhuma família está com visitadora e que, quando houver novas contratações, ela terá uma. Assim como os demais, entendo que ela também demonstra ter dificuldades em se organizar com as crianças; outro menino (de mais ou menos um ano), por exemplo, fica engatinhando naquele espaço, se prende embaixo da cadeira em que estou sentada, chora, vai para a rua, e ela não vê o que está acontecendo, tampouco vai atendê-lo ou presta atenção ao que é trabalhado. Percebia, em muitos momentos, que era a menina de 6 anos que cuidava de suas(seus) irmãs(irmãos) menores, buscando-os(as) na rua, carregandoos(as) e colocando-os(as) no colo, alcançando a mamadeira ou a chupeta e, quando partiam, empurrava o carrinho com dois dos seus irmãos menores dentro, naquelas ruas esburacadas $e$ de chão batido (DC).

Constatava que, ao tentar aderir ao PIM, Elena, assim como as outras mulheres, buscava ampliar o próprio acesso, bem como o de sua família, aos chamados equipamentos do Estado. Solicitar o atendimento de uma visitadora significava vincular-se à política, ${ }^{13}$ assim como ampliar as formas de obter atenção, reconhecimento, participação e aprendizagens, aspectos importantes para qualquer indivíduo e que sugeriam a formação de um pertencimento, configurado pela sociabilidade ali proposta. Apesar de suas dificuldades, Elena mostrava-se bastante independente em relação aos seus compromissos; certa vez, contou-me que havia ido a Canoas (RS), referindose ao centro da cidade, para receber o PBF ou a pensão do seu filho que possui deficiência física e mental, para fazer algum documento ou procurar um médico ou especialista para um(a) de seus(suas) filhos(as).

Em um desses encontros, narrou-me sua ida ao médico (otorrino) para examinar a bebê, Manuela, que havia sido encaminhada ao especialista pela Unidade Básica de Saúde (UBS), com suspeita de não estar ouvindo bem. ${ }^{14}$ Durante grande parte dos encontros, Manuela ficava no berço e mexia-se pouco - seu corpo parecia acostumado com aquela situação. Certo dia, durante a realização de uma atividade grupal, eu disse para Elena pegá-la mais no colo e conversar com ela, ao que a mãe rapidamente respondeu: "ela precisa se acostumar a ficar no berço"; porém, em seguida, foi em direção à filha e, carinhosamente, atendeu à minha solicitação. Perguntei-lhe o que o médico havia dito sobre a audição de Manuela, e ela respondeu: "Está tudo bem, ela não tem nada", buscando encerrar a nossa conversa. Talvez não tivesse entendido (ou pudesse dar conta) das solicitações do médico ou não conseguisse cumprir os encaminhamentos posteriores à consulta, como a realização de exames, o que envolve horários, autorizações, filas, locomoção, reconsultas, alguém para ficar com as crianças etc., mas demonstrava entender que aquela resposta iria silenciar-me. Conviver com Elena nos mostrava que ora ela procurava corresponder à linguagem do cuidado e do desenvolvimento infantil ali proposto, ora precisava romper com os controles biopolíticos exercidos sobre as mulheres e as maternidades e que talvez não conseguisse cumprir (Fernanda CRUZ, 2015; KLEIN, 2010).

Em outro dia, Elena foi a última a chegar ao encontro, com João, Tamara, Daniela, Gabriel e Manuela. O técnico já estava contando uma história ao grupo, mas Elena entrou gritando para contar que Tamara fora atropelada pela Kombi que levava João ao Pestalozzi, a escola especial que ele frequentava. Disse que a menina levou muitos pontos na cabeça, que ela não viu quando a criança foi para frente da Kombi, nem o motorista viu, e que foram os vizinhos que gritaram para avisar que Tamara estava debaixo da Kombi. Elena contou aquele fato como quem ganha visibilidade e importância, mostrando o rosto da filha, que estava machucado, os pontos na cabeça e as marcas que ainda estavam em suas costas. Então, o técnico interrompeu a história e perguntou-lhe: "Tu estás levando ao médico?". Elena respondeu: "Todos os dias", e sorriu, parecendo confirmar ter aprendido que aquela era a forma mais adequada de responder ao que the era solicitado como mãe e cuidadora; mas eu ainda podia pensar na resposta e no sorriso como formas de resistir, de escapar, ou seja, de encontrar uma saída para aquilo que ela não conseguia cumprir (com tantos(as) filhos(as), dificuldades cognitivas e materiais) ou que não fazia sentido para ela. ${ }^{15}$ Provavelmente, ela não ignorava a repercussão que um acidente podia

\footnotetext{
${ }^{13}$ A modalidade de atenção individual ocorria semanalmente nos domicílios, desenvolvida pela visitadora.

${ }^{14}$ Com o tempo, fui percebendo que todos(as) os(as) filhos(as) menores de Elena recebiam encaminhamento para avaliação auditiva e neurológica, pois não respondiam dentro do esperado a estímulos visuais e sonoros.

15 Os dados que não estão nos excertos, aqui descritos e analisados sobre Elena, foram produzidos e recompostos por meio do trabalho etnográfico.
} 
ter, mas essa história delineia um pouco de sua forma de cuidar de seus(suas) filhos(as) em meio às possibilidades e recursos que era capaz de acionar. Olhei para Manuela (já com três meses), que estava no berço, suja e muito picada no rosto pelos mosquitos. Agora sabíamos o motivo para Elena não ter comparecido no encontro anterior: o atropelamento de Tamara.

Enquanto as atividades eram desenvolvidas, os(as) filhos(as) de Elena dispersavam-se. Olhando-a como mãe e "cuidadora", pensava que ela conseguia dar atenção a apenas uma ou duas crianças de cada vez. Manuela, com meses de vida, frequentemente era deixada no carrinho. Certa vez, precisei interromper a brincadeira de outras crianças, de mais ou menos anos de idade, que tentavam Ihe dar a mamadeira enquanto ela se engasgava. Gabriel, de um ano e meio, engatinhava pela Associação, não falava e constantemente ia para a rua e tentava pegar a chupeta e os alimentos das outras crianças, que o afastavam. Tamara, de 3 anos, comparecia a poucos encontros, pois geralmente dormia na casa da avó, mãe de Elena. Observei que, quando as crianças de Elena tentavam estabelecer contato com outras crianças para brincar, alcançar alimentos, mamadeiras ou a chupeta, eram "sutilmente" afastadas, provavelmente pelas diferenças, que se mostravam visíveis.

Ao longo dos encontros, Elena contava-nos sobre sua vida, sobre a prisão, os vícios e as atitudes do marido, sobre quem dormia com quem em cada uma das (duas) camas, sobre a perda de um filho de 6 anos, sobre os conflitos, os afetos e as dificuldades que a cercavam. Ela nos contou sobre Tamara, que não podia ficar sem a avó para dormir, demonstrando a "circulação" e a necessidade de ampliação de uma rede de cuidados (FONSECA, 2005). Daniela, de 6 anos, quase não falava, apenas sorria, colocava as mãos na boca e tentava ora se esconder, ora se encostar em algum(a) de nós, buscando alguma forma de atenção e afeto. Nas festas que realizávamos, quando alguém anunciava ao microfone uma criança perdida, podia-se saber que era uma das crianças de Elena. Havia ainda José, com 8 anos, que frequentava a escola, mas também comparecia aos encontros do PIM; João, com 12 anos, que também era assíduo nos encontros; e outra filha, de 15 anos, que morava com a primeira sogra de Elena.

Trago, de forma rudimentar, alguns aspectos da história de Elena, que se mostrava emblemática. Ela fazia-me refletir e colocar sob tensão os ensinamentos e as orientações divulgadas nos "Guias" e nas atividades propostas pelo PIM, que, de antemão, pareciam pressupor a falta de cuidado e de estímulos às crianças por parte das famílias pobres, bem como a existência de uma mãe que pudesse ou devesse se tornar mais "competente" para reverter tal situação. Mas como dar conta de "ensinar" Elena a ser a "cuidadora" idealizada pelo Estado e descrita pelos "Guias", cujos ensinamentos se ancoravam, principalmente, nos saberes médicos e psicológicos, que tomavam como regra uma estrutura individual, cognitiva, material e econômica que ela (assim como outras mulheres que conheci) demonstrava não possuir? Indagava, ainda, em que medida os saberes divulgados pelo PIM levavam em conta os conhecimentos e as experiências das mulheres de "carne e osso" como Elena. Será que as propostas e as ações apresentadas em políticas como o PIM são suficientes (e eficientes) para dar conta de diminuir (pelo conhecimento), conforme seus objetivos, a vulnerabilidade de crianças de 0 a 6 anos, como os(as) filhos(as) de mulheres como Elena? Quantas coisas "a mais" Daniela, de 6 anos, precisava aprender a fazer para dar conta de cuidar de seus(suas) irmãos(irmãs)? O que Daniela fazia em relação ao cuidado de seus(suas) irmãos(irmãs) menores, assim como outras crianças que conheci, geralmente meninas de 8 a 10 anos, provavelmente ia muito além do que estava previsto nas formulações da política, e isso, mais uma vez, escapava da previsibilidade das linguagens que ancoravam as ações ali propostas.

Questionar acerca da responsabilização materna no âmbito das políticas públicas, como o PIM (e também o PCF e o PBF), significava reconhecer alguns aspectos de sua produção, capazes de (re)inscrever as mulheres (e homens) numa matriz regulatória de gênero, binária, heterossexual e cisgênera (DETONI; MACHADO; NARDI, 2018).

Para meninas como Daniela, faltavam vivências e oportunidades que meninas de classe média, certamente, conheciam muito bem: escola, material escolar, lazer, brinquedos, vestuário, alimentação; isso indicava o quanto a ênfase na "criança natural", associada às políticas de normalização preconizadas pelo Estado, era equivocada. Pode-se pensar, a partir desse exemplo, que ser criança, tal como é preconizado nos "Guias" e em muitas ações governamentais, significa muito mais do que pertencer a uma determinada faixa etária, ou entender as características do desenvolvimento infantil a fim de realizar as intervenções pedagógicas "adequadas" para cada idade; significa que a infância, assim como outros períodos da vida, está atravessada por condições de vida muito concretas, ligadas a condições sociais, culturais e políticas, como abordei anteriormente (Patrice SCHUCH; FONSECA, 2009).

Essa história também desconstruía noções naturalizadas de instinto materno e da "mãe natural" e "adequada", além de romper com algumas ênfases educativas apresentadas por políticas como o PIM, que buscam ensinar e conduzir, ordenada e progressivamente, as maternidades. Romper com as proposições de cuidado e de saúde ligadas a uma feminilidade homogênea, universal e natural torna visível a relação de poder-saber que institui e legitima uma 
noção hegemônica de maternidade, resistindo a ela e pluralizando-a. Esse enfoque permitiame analisar em que medida o gênero, inscrito nos sistemas linguísticos e simbólicos, passava a funcionar como um elemento constitutivo das relações familiares, tornando as mulheres e as maternidades um lugar privilegiado de investimento por parte do Estado. Compreender o gênero e as maternidades em seu aspecto polissêmico, inacabado e conflitivo possibilitava seguir na contramão de proposições e prescrições educativas homogeneizadoras.

Elena demonstrava ser a mantenedora da casa e agia como tal. Ela me fazia pensar nas noções normatizadas de família e maternidade que embasam as políticas públicas, na importância de relativizar o que entendíamos por cuidado e negligência. Demonstrava encontrar estratégias próprias para ampliar alguns aspectos de vida, como "vender alho ou panos de prato" na rua, "pedir" e "trocar" o que ganhava (roupas, cobertas, calçados) e, ainda, ter respostas rápidas para as perguntas dos(as) técnicos(as) sobre o cuidado e a saúde das crianças, tal qual eles(as) quisessem ouvir. Será que Elena podia ser considerada uma cuidadora negligente? Por pertencer a uma família considerada em "situação de vulnerabilidade social", será que os serviços públicos oferecidos eram suficientes e estavam ao seu alcance? Entendia que ela negociava e criava recursos importantes para dar conta de suas tarefas/responsabilidades, cumprindo alguns horários estabelecidos, esquecendo-se de outros, saindo para receber o salário do PBF, pedindo na rua, trocando algumas coisas que ganhava, comprando alimentos e, dentro das suas possibilidades, alimentando as crianças, levando-as ao posto médico e a outras consultas, reivindicando a visita de uma visitadora, comparecendo às reuniões do PIM, às reuniões do CRAS do município, às solicitações do Conselho Tutelar etc.

Em vários encontros, Elena solicitou o trabalho de uma visitadora, indagando: "Já tem uma visitadora para mim?", o que significava admitir que o PIM, de acordo com a sua metodologia, se mantinha desativado, fazendo-nos refletir, mais uma vez, acerca da dimensão programática da vulnerabilidade. Elena não só demonstrava seu desejo em vincular-se à política, como também explicitava a necessidade concreta de obter apoio de uma ampla rede social. Ficava difícil refletir sobre a diminuição da vulnerabilidade das crianças, extensamente preconizada por essas políticas, sem cogitar a responsabilização do Estado, mediante o acesso qualificado a serviços públicos. Podíamos pensar que a vulnerabilidade das crianças era precedida de "múltiplos abandonos" daquela família (e daquela mulher), raciocínio geralmente esquecido diante das propostas governamentais com foco na responsabilização das famílias (FONSECA; Andrea CARDARELLO, 2009; FONSECA, 2012). Ao mesmo tempo, e apesar de todo o quadro que ia constituindo o que reconhecíamos como sendo os "limites" de Elena, durante todo o trabalho de campo que realizei, em nenhuma vez se falou na possibilidade de conversar ou produzir alguma ação com o pai daquelas crianças.

Problematizar a feminização que as políticas públicas incorporam, a naturalização do amor e do cuidado ligado à consanguinidade, assim como a ausência e/ou abandono paterno, podem ser caminhos transformadores para compreender e ressignificar as políticas de Estado. Para isso, precisamos reconhecer o caráter de construção social do "gênero como uma matriz regulatória inscrita na linguagem, que tem como um de seus efeitos a produção da materialidade dos corpos" constituintes nas/das relações de gênero, de maternidade e paternidade (DETONl; MACHADO; NARDI, 2018, p. 2).

Sarti (2008) nos faz refletir sobre como os alicerces da família vêm passando por processos de mudanças substantivas ao longo dos tempos. Para ela, falar em famílias, no Brasil, neste início de século, significa esgarçar os laços que as delimitam. Para relativizar e desestabilizar as idealizações (ou engessamentos) relacionadas às famílias nos dias atuais, Sarti diz que não se pode saber de antemão o que é adequado ou inadequado ao nos referirmos à família, lançando um conjunto de questões que considero relevantes:

No que se refere às relações conjugais, quem são os parceiros? Que família criaram? Como delimitar a família se as relações entre pais e filhos cada vez menos se resumem ao núcleo conjugal? Como se dão as relações entre irmãos, filhos de casamentos, divórcios, recasamentos de casais em situações tão diferenciadas? Enfim, a família contemporânea comporta uma enorme elasticidade (SARTI, 2008, p. 25).

Esse conjunto de questões leva-nos a romper com qualquer conceito que busque fixar, naturalizar ou estreitar nossos entendimentos sobre família (e uma relação natural entre maternidade, saúde e cuidado), conduzindo-nos a pensar na heterogeneidade e na complexidade presentes nessa discussão, no sentido de apreender que as redes de parentesco, conforme Fonseca (2005, p. 50), podem estender-se "além do grupo consanguíneo e da unidade doméstica". Utilizo essas referências para refletir sobre algumas formas de intervenção que estão no bojo de políticas sociais contemporâneas, voltadas para a educação (e as competências) das famílias, e para considerar que partir de um modelo idealizado ou "natural" diminui muito a nossa compreensão das necessidades das famílias brasileiras, especialmente das mais pobres. 
Embora tenha convivido com outras mulheres-mães daquela comunidade, considerei importante detalhar minhas observações sobre Elena para discutir um pouco do contexto em que reuni elementos e informações que me possibilitassem compreender e problematizar aspectos das formas de negociar, socializar-se, aprender e resistir daquelas mulheres e de suas famílias. Também busquei apreender limitações muito concretas dos ensinamentos propostos pelo PIM, o que indicava a necessidade de refletir sobre as maternidades, em meio às noções de educação, saúde, cuidado, negligência, estímulo, aprendizagem, dentre outras que nos são apresentadas como "dadas", colocando-as sob rasura e/ou ampliando-as.

Para finalizar, quero dizer que as mulheres atendidas pelo PIM não estão, necessariamente, representadas na história de Elena, mas muito de suas vivências e dificuldades parecia convergir ali, reunindo um conjunto de confrontos e desafios para as políticas de inclusão social. Tais problemáticas eram constitutivas das vidas de muitas mulheres e famílias e traziam junto algumas formas inusitadas e possíveis de enfrentamento que, em muitos momentos, podem nos fazer refletir sobre significações hegemônicas, incorporadas às práticas de quem se propõe a ensinar, e questioná-las. Tais experiências podem ainda nos levar a problematizar uma linguagem salvacionista que permeia a(s) política(s), principalmente por parte do Estado (RIO GRANDE DO SUL, 2016a; 2016b), cabendo indagar acerca do alcance e dos efeitos que os seus ensinamentos podem ter, atrelados às relações de gênero, e que, muitas vezes, escapam da lógica do controle, sob a qual alguns podem (acreditar) ter o poder de organizar o que está desorganizado, de incluir ou de curar o que está carente ou doente. Se o conceito de gênero possibilita-nos pensar o caráter plural e ambivalente das feminilidades (e masculinidades), e que estas representações não se sobrepõem, necessariamente, a homens e a mulheres, torna-se potente, justamente, o exame das feminilidades/maternidades em sua relação com educação, saúde e cuidado, em seus aspectos de multiplicidade e provisoriedade e no caráter construído das relações de gênero.

\section{Referências}

BADINTER, Elisabeth. Um amor conquistado: o mito do amor materno. Rio de Janeiro: Nova Fronteira, 1985.

BRASIL. Ministério do Desenvolvimento Social e Agrário. Programa Criança Feliz. A intersetorialidade na visita domiciliar. Brasília, 2017.

BRASIL. Ministério do Desenvolvimento Social e Combate à Fome. Bolsa Família: Agenda de Compromissos da Família, 2006.

CANELA. Prefeitura Municipal. Como realizar a semana do bebê em seu município: 10 anos priorizando a primeira infância em Canela. Prefeitura Municipal de Canela, ULBRA. Brasília: UNICEF/ Brasil, 2010.

CRUZ, Fernanda. "Da maternidade como invenção de novas possibilidades de vida: análise das experiências de 'egressas' de serviços de acolhimento institucional". Civitas, Porto Alegre, v. 15, n. 2, p. 326-341, abr./jun. 2015.

DEL PRIORE, Mary. Ao sul do corpo. Condição feminina, maternidades e mentalidades no Brasil Colônia. Rio de Janeiro: Livraria José Olympio, 1993.

DETONI, Priscila Pavan; MACHADO, Paula Sandrine; NARDI, Henrique Caetano. "'Em nome da mãe': performatividades e feminizações em um CRAS". Revista Estudos Feministas [online], v. 26, n. 1, e45084. Disponível em https://www.scielo.br/scielo.php?pid=S0104-026X2018000100210\&script=sci abstract\&tIng=pt. Epub 15/01/2018. ISSN 1806-9584. https://dol.org/10.1590/18069584.2018v26n145084. Acesso em 09/10/2020.

FREIRE, Maria Martha de Luna. "'Ser mãe é uma ciência': mulheres, médicos e a construção da maternidade científica na década de 1920". História, Ciências, Saúde - Manguinhos, Rio de Janeiro, v. 15, supl., p. 153-171, jun. 2008.

FREIRE, Maria Martha de Luna. "A puericultura em revista". Physis, Rio de Janeiro, v. 24, n. 3, p. 973-993, jul./set. 2014. Disponível emhttp://www.scielo.br/scielo.php?script=sci_arttext\&pid=S0103$73312014000300973 \&$ lng =pt\&nrm=iso. Acesso em 09/10/2020.

FONSECA, Claudia; CARDARELLO, Andrea. "Direitos dos mais ou menos humanos". In: FONSECA, Claudia; SCHUCH, Patrice (Orgs.). Políticas de proteção à infância: um olhar antropológico. Porto Alegre: EDUFRGS, 2009. p. 219-252. 
FONSECA, Claudia. "Concepções de família e práticas de intervenção: uma contribuição antropológica". Saúde e Sociedade, São Paulo, v. 14, n. 2, p. 50-59, 2005.

FONSECA, Claudia. "Quando cada caso não é um caso: Pesquisa etnográfica e educação". Revista Brasileira de Educação, Rio de Janeiro, n. 10, p. 58-78, 1999.

FONSECA, Claudia. "Mães 'abandonantes': fragmentos de uma história silenciada". Revista Estudos Feministas, Florianópolis, v. 20, n. 1, p. 13-32, abr. 2012. Disponível em http://www.scielo.br/scielo. php?script=sci_arttext\&pid=S0104-026X201 2000100002\&lng=en\&nrm=iso. Acesso em 09/10/2020.

KLEIN, Carin. "A produção da maternidade no Programa Bolsa-Escola". Revista Estudos Feministas, Florianópolis, v. 13, n. 1, p. 31-52, jan./abr. 2005.

KLEIN, Carin. Biopolíticas de inclusão social e produção de maternidades e paternidades para uma "infância melhor". 2010. Tese (Doutorado) - Programa de Pós-Graduação em Educação, Universidade Federal do Rio Grande do Sul, Porto Alegre, RS, Brasil.

KLEIN, Carin. "Discursos que (re)atualizam a produção de infância e maternidade em políticas de inclusão social". Textura, Canoas, v. 20, n. 43, p. 53-78, maio/ago. 2018.

MARTIN, Emily. A mulher no corpo - Uma análise cultural da reprodução. Rio de Janeiro: Garamond, 2006.

MARTINS, Ana Paula Vosne. "'Vamos criar seu filho': os médicos puericultores e a pedagogia materna no século XX". História, Ciência e Saúde, Manguinhos, v. 15, n. 1, p. 135-154, 2008.

MEYER, Dagmar. "A politização contemporânea da maternidade: construindo um argumento". Gênero: Núcleo Transdisciplinar de Estudos de Gênero, Niterói, v. 6, n. 1, p. 81-104, 2006.

MEYER, Dagmar. "Gênero e educação: teoria e política". In: LOURO, Guacira; NECKEL, Jane Felipe; GOELLNER, Silvana (Orgs.). Corpo, Gênero e Sexualidade: um debate contemporâneo na educação. 5. ed. Petrópolis: Vozes, 2017.

NICHOLSON, Linda. "Interpretando o gênero". Revista Estudos Feministas, Florianópolis, v. 8, n. 2, p. 9-41, 2000.

PEREIRA, André Ricardo. "A criança no Estado Novo: uma leitura na longa duração". Revista Brasileira de História, São Paulo, v. 19, n. 38, p. 165-198, 1999.

O'REILLY, Andrea. Matricentric feminism: Theory, activism, and practice. Toronto: Demeter Press, 2016.

PEDRO, Joana Maria. "Aborto e infanticídio: práticas muito antigas". In: PEDRO, Joana Maria (Org.). Práticas proibidas: práticas costumeiras de aborto e infanticídio no século XX. Florianópolis: Cidade Futura, 2003. p. 19-57.

RAGO, Margareth; VEIGA-NETO, Alfredo. Figuras de Foucault. Belo Horizonte: Autêntica, 2006. p. 75-85.

$\mathrm{RICH}$, Adrienne. Of woman born: Motherhood as experience and institution. Nova lorque/Londres: WW Norton \& Company, 1995.

RIO GRANDE DO SUL. Programa Primeira Infância Melhor. Secretaria Estadual de Saúde. Departamento de Ações em Saúde. O que é. [online]. Porto Alegre: Secretaria Estadual de Saúde, 2020. Disponível em http://www.pim.saude.rs.gov.br/site/o-pim/o-que-e/. Acesso em 09/10/2020.

RIO GRANDE DO SUL. Secretaria da Saúde. Programa Primeira Infância Melhor. Guia da Família. 7. ed. Porto Alegre: CORAG, 2016a.

RIO GRANDE DO SUL. Secretaria da Saúde. Programa Primeira Infância Melhor. Guia da Gestante. 7. ed. Porto Alegre: CORAG, 2016b.

RIO GRANDE DO SUL. Secretaria da Saúde. Programa Primeira Infância Melhor. Guia de Orientação para GTM, Monitor e Visitador. Contribuições para políticas na área do desenvolvimento infantil. Porto Alegre: Relâmpago, 2007.

SARTI, Cynthia. "Famílias e Jovens: no horizonte das ações". Revista Brasileira de Educação, Rio de Janeiro, n. 11, p. 99-109, maio/ago. 1999. 
SARTI, Cynthia. "Famílias enredadas". In: ACOSTA, Ana Rojas; VITALE, Maria Amália (Orgs.). Famillia: redes, laços e políticas públicas. 4. ed. São Paulo: Cortez, 2008. p. 31-50.

SCAVONE, Lucila. Dar a vida e cuidar da vida: feminismos e ciências sociais. São Paulo: EDUNESP, 2004.

SCHWENGBER, Maria Simone. Donas de Si? A educação de corpos grávidos no contexto da Pais \& Filhos. 2006. Tese (Doutorado) - Programa de Pós-Graduação em Educação, Universidade Federal do Rio Grande do Sul, Porto Alegre, RS, Brasil.

SCOT, Joan. "Fantasy Echo: História e a construção da identidade". Labrys [online], n. 1-2, jul./dez. 2002. Disponível em https://www.labrys.net.br/labrys1_2/scott1.html. Acesso em 09/10/2020.

SCHUCH, Patrice; FONSECA, Claudia. "Introdução". In: FONSECA, Claudia; SCHUCH, Patrice (Orgs.). Políticas de proteção à infância: um olhar antropológico. Porto Alegre: EDUFRGS, 2009. p. 9-17.

TOMAZ, Renata. "Feminismo, maternidade e mídia: relações historicamente estreitas em revisão". Galaxia, São Paulo, n. 29, p. 155-166, jan./jun. 2015. Disponível em https://www.scielo.br/pdf/gal/ n29/1982-2553-gal-29-0155.pdf. Acesso em 09/10/ 2020.

ZANELLO, Valeska. Saúde Mental, Gênero e Dispositivos: Cultura e Processos de Subjetivação. Curitiba: Appris, 2018.

Carin Klein (carin.klein@ulbra.br) é doutora em Educação pela Universidade Federal do Rio Grande do Sul (UFRGS). Membro do Grupo de Estudos de Educação e Relações de Gênero (GEERGE/UFRGS). Professora do Programa de Pós-Graduação em Educação e do Curso de Pedagogia da Universidade Luterana do Brasil (ULBRA/RS). Seus interesses de pesquisa direcionamse para as temáticas de gênero, maternidade, infância, juventudes, educação e políticas públicas de inclusão social.

\section{COMO CITAR ESSE ARTIGO DE ACORDO COM AS NORMAS DA REVISTA}

KLEIN, Carin. "Maternidades em contextos educativos do PIM/RS". Revista Estudos Feministas, Florianópolis, v. 29, n. 1, e62011, 2021.

\section{CONTRIBUIÇĀO DE AUTORIA}

Não se aplica.

\section{FINANCIAMENTO}

Não se aplica.

\section{CONSENTIMENTO DE USO DE IMAGEM}

Não se aplica

\section{APROVAÇĀO DE COMITÊ DE ÉTICA EM PESQUISA}

Não se aplica.

\section{CONFLITO DE INTERESSES}

Não se aplica.

\section{LICENÇA DE USO}

Este artigo está licenciado sob a Licença Creative Commons CC-BY 4.0 International. Com essa licença você pode compartilhar, adaptar, criar para qualquer fim, desde que atribua a autoria da obra.

\section{HISTÓRICO}

Recebido em13/03/2019

Reapresentado em 16/10/2020

Aprovado em 26/10/2020 